\title{
High quality oral health - an FDI World Dental Federation objective
}

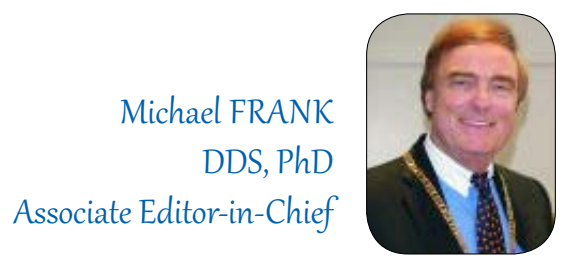

Dear Readers,

It is my pleasure to write to you as the new President of the European Regional Organization of our FDI World Dental Federation, and 1 would like to take this opportunity to share some insights from the most recent developments in international policies for our profession. Globalization is a buzzword we have been hearing repeatedly in the media, and yes, the world is most certainly converging in terms of sharing information, data transfer, transport, trade and international financial flows. At the same time, the regions and nations of this globalized world still differ enormously in terms of their standards of living and, not in the least, their access to health care. Reducing global health inequality and tackling global health problems effectively, efficiently and sustainably were the objectives of the annual congress of the FDI World Dental Federation, held in San Francisco from 2 to 8 September, 2019. 1 would like to take this opportunity to tell you about the most important resolutions adopted at this meeting.

Visions for global oral health

The FDl's current strategic plan - the policy paper in which the goals of our international dental cooperation are defined covers the years 2018 to 2021 and will therefore come to an end in two years' time. For this reason, some time ago we tasked a new working group with drawing up a new strategic plan for the FDI World Dental Federation for the period until 2030. Prof. Michael Glick (USA) and Prof. David Williams (UK) were appointed to lead this working group, and my German colleague Dr. Michael Sereny is also part of it. The key points of the plan so far are that oral health must be accessible, available and affordable worldwide. It should be integrated into the overall health agenda; this will ensure that dentists are empowered under the UN goals for sustainable development. We want to build a responsive and robust profession worldwide and we want oral health to be firmly anchored in the global discourse on health and sustainability. One point that is very important for everyone involved is to ensure that the draft of our new strategic plan, Vision 2030, is not an immutable doctrine, but instead a document that can be changed or adapted at any time. We want technical feedback and constructive criticism to be easily incorporated into the new paper, which we hope to have ready as a final draft to present to the FDI General Assembly in 2020.

New FDl policy statements

An important aspect of the work of our federation is to produce and publish information and guidelines on all aspects of oral health care and the actions of dentists worldwide. We do this with the FDI Policy Statements, which sum up our thoughts and views on a wide variety of issues and topics related to our profession, its practice and oral health. These statements are the result of long and intensive discussions and consultations with respected experts from around the world. Many of our statements are prepared by scientific committees specifically set up to debate and write them. Other statements are the result of professional collaboration between our association and other associations such as the World Health Organization (WHO). 
While in San Francisco the voting delegates of the FDI member organizations adopted policy statements on the following topics:

O Access to Oral Healthcare Among Vulnerable and Underserved Populations

O Antibiotic Stewardship in Dentistry

O Continuing Education via eLearning

O Ethical International Recruitment of Oral Health Professionals (this is a revised and updated version of the 2006 statement). Updated issues included a commitment not to solicit dental professionals. As the FDl we fully align ourselves with the World Health Organization's (WHO) Code of Practice on the Ethical Recruitment of Health Professionals.

$O$ infection Prevention and Control in Dental Practice (revised and updated version of the 2009 state-ment)

O Malocclusion in Orthodontics and Oral Health

O Carious Lesions and First Restorative Treatment

O Repair of Restorations

Our new Policy Statements will be published shortly in English and German on the FDI website:

(https:/ /www.fdiworlddental.org/resources/policy-statements).

A new President and forward-looking elections

Like most political professional bodies, the World Dental Federation has a democratic structure. Elections to the FDI Council and the standing committees on a range of topics are part of every General Assembly.

In San Francisco, the former President-elect, Dr. Gerhard Seeberger (1taly), was elected President of the FDI, leaving the post of his designated successor to be filled. The General Assembly elected Professor Ihsane Ben Yahya (Morocco) to the office of President-elect in two ballots. In accordance with the FDI constitution, she will take up the office of President of the World Federation in 2021. Dr.]ack Cottrell (Canada) and Dr. Peter Engel (Germany) had also stood for election.

Dr. Greg Chadwick (USA) took over the office of treasurer.

Dr.Juliane von Hoyningen-Huene, one of my German colleagues, was appointed chair of the FDI Women Dentists Worldwide Section.

For me personally, the congress in San Francisco marked a very fruitful and collegial cooperation of dentists from all over the world, and it was a source of pleasure and inspiration. The results of the congress encourage me to hope that in the not too distant future we will be able to work together to balance or even eliminate the dramatic differences in access to highquality oral health care that exist around the world, and to ensure that everyone, everywhere benefits from the best possible oral health care - thus creating true globalization. 1 cordially invite you, dear colleagues and all readers of the Stomatology Edu Journal, to work with us to achieve this goal!

Yours sincerely,

Michael Frank, DDS, PhD

ERO President of FDI World Dental Federation

President Dental Chamber Hesse

Board of the German Dental Chamber

Associate Editor-in-Chief of the Stomatology Edu Journal

DOI: https://doi.org/10.25241/stomaeduj.2019.6(3).edit.1 